\title{
Leprosy in Zimbabwe
}

\author{
N F LYONS \& B P B ELLIS \\ Department of Medical Microbiology, Godfrey Huggins School \\ of Medicine, University of Zimbabwe, Salisbury, Zimbabwe
}

Received for publication 26 April 1982

Summary In Zimbabwe, as in many countries in Africa, leprosy is an endemic disease. The known incidence is approximately 2 cases per 1,000 population and 350 new cases are seen annually.

Many factors have influenced the spread of the disease including the recent bush war but progress in control measures is being made.

\section{Introduction}

Zimbabwe covers an area of $390,757 \mathrm{~km}^{2}$ and is bordered by Zambia, Moçambique, South Africa and Botswana. The country is divided into five provincial areas: Manicaland, Mashonaland, Midlands, Matabeleland and Victoria (Fig. 1).

The last census was taken in 1969, and more recent estimates put the population at $6,625,000$, comprising $5,750,000$ Blacks, with the remainder Whites, Asians or Coloureds. The Blacks form two predominant groups, each stemming from separate ethnic origins. The numerically superior Shona were the original inhabitants of the area, and the Matebele an off-shoot of the Zulu nation of South Africa.

Situated between the Equator and the Tropic of Capricorn, Zimbabwe experiences a sub-tropical climate owing to the relatively high altitude. A dry season occurs between April and October, and the main rains, delivering a mean annual precipitation of $730.5 \mathrm{~mm}$, fall between November and February.

Politically, the country was administered by the British South Africa Company from 1889 until 1922, when it became a British colony. As Southern Rhodesia it became a member of the ill-fated Federation of Rhodesia and Nyasaland from 1953 until 1963. Assuming the name Rhodesia until 1978, political events saw the change through Zimbabwe-Rhodesia to Zimbabwe, with attainment of legal independence in April 1980.

A bush war engulfed most of the country between 1973 and 1979. During this period, health services were severely disrupted and large numbers of the 


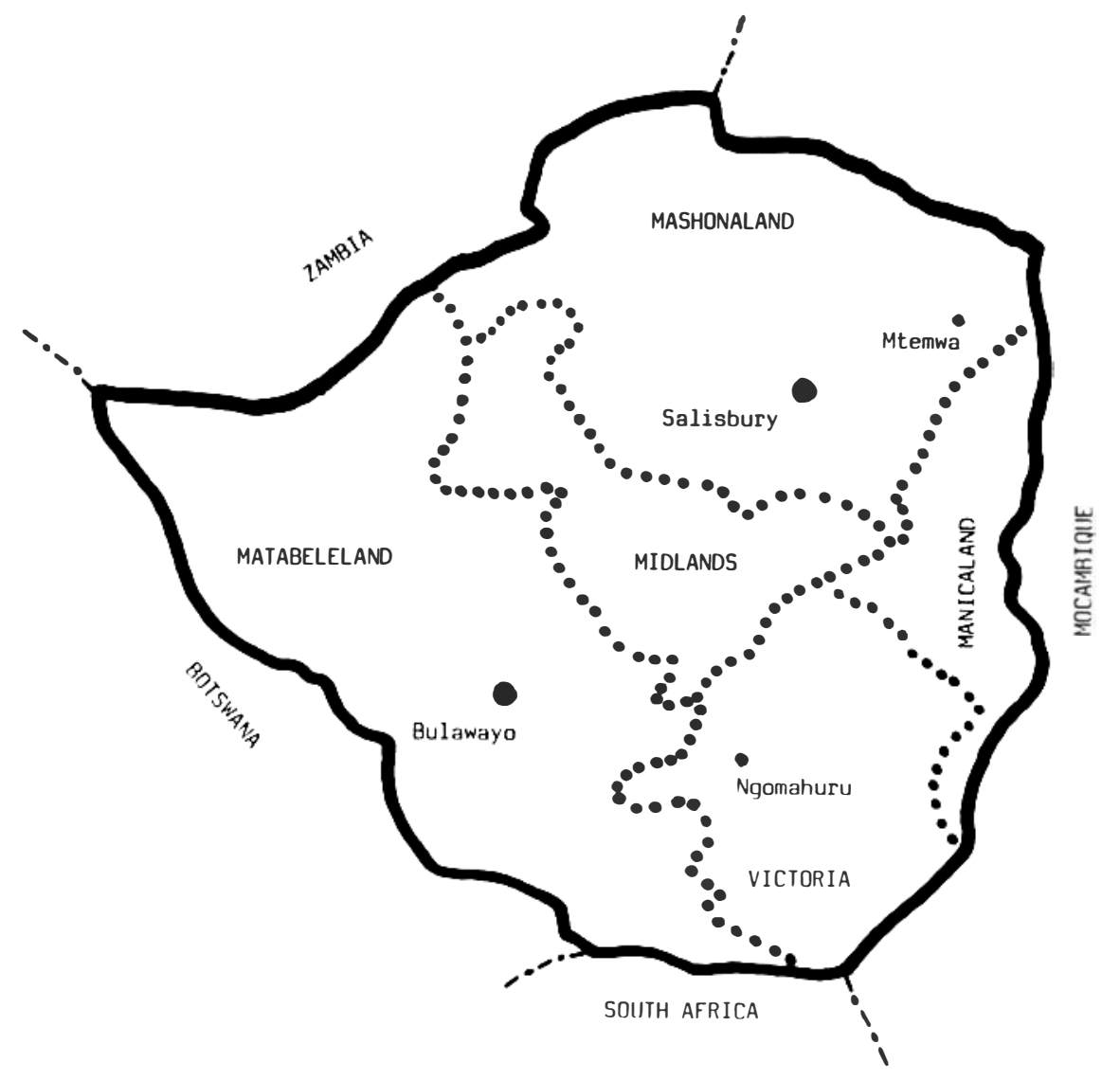

Figure 1. Zimbabwe, showing Provinces and sites of Mtemwa and Ngomahuru Hospitals.

Black population migrated to urban areas or were moved to 'protected villages'. Many fled as refugees to neighbouring countries.

The major health problem is malnutrition and many diseases of microbiological aetiology are present. An expanded vaccination programme is currently being undertaken which hopefully will control, among others, measles and other childhood diseases. Malaria, schistosomiasis and many other parasitic diseases are common. Tuberculosis and typhoid are frequently seen and outbreaks of bubonic plague, cholera and anthrax have occurred.

\section{Leprosy - historical review}

Leprosy is endemic in Zimbabwe. The earliest authenticated reference to the disease is found in the report of the Ministry of Health for 1903, where the District Surgeon for Bulawayo reported 'several cases of leprosy'. 
Early statistics of known cases are highly erroneous and reflect the inhumanity of the Leprosy Repression Act of $1919^{3}$, and the associated regulations. This required that leprosy patients be detained in asylums and also made provision for legal action against any person 'harbouring a leper' and patients who escaped from an asylum. Undoubtedly, many patients remained in hiding being sheltered by their families and friends.

Two 'leper settlements' were established. One of these, at Ngomahuru in the Victoria District, is now a tuberculosis hospital, and the second, at Mtemwa, still houses 70 welfare patients to-day.

A total of 5,299 patients were admitted to these hospitals during the period 1925-1962. The number of aliens compared to indigenous cases is remarkable (Fig. 2). Many of these people were part of the immigrant labour force employed in mines and on farms and who lost their jobs as a result of the disability caused by the disease. Destitution forced them to seek the protection offered in the settlements. Another contributing factor to the high alien figure is that many were suffering from or incubating the disease when they left their countries of origin (Table 1).

Despite the anathema of the policy of enforced hospitalization, it did permit a statistical evaluation of the geographic distribution of the disease (Table 2),

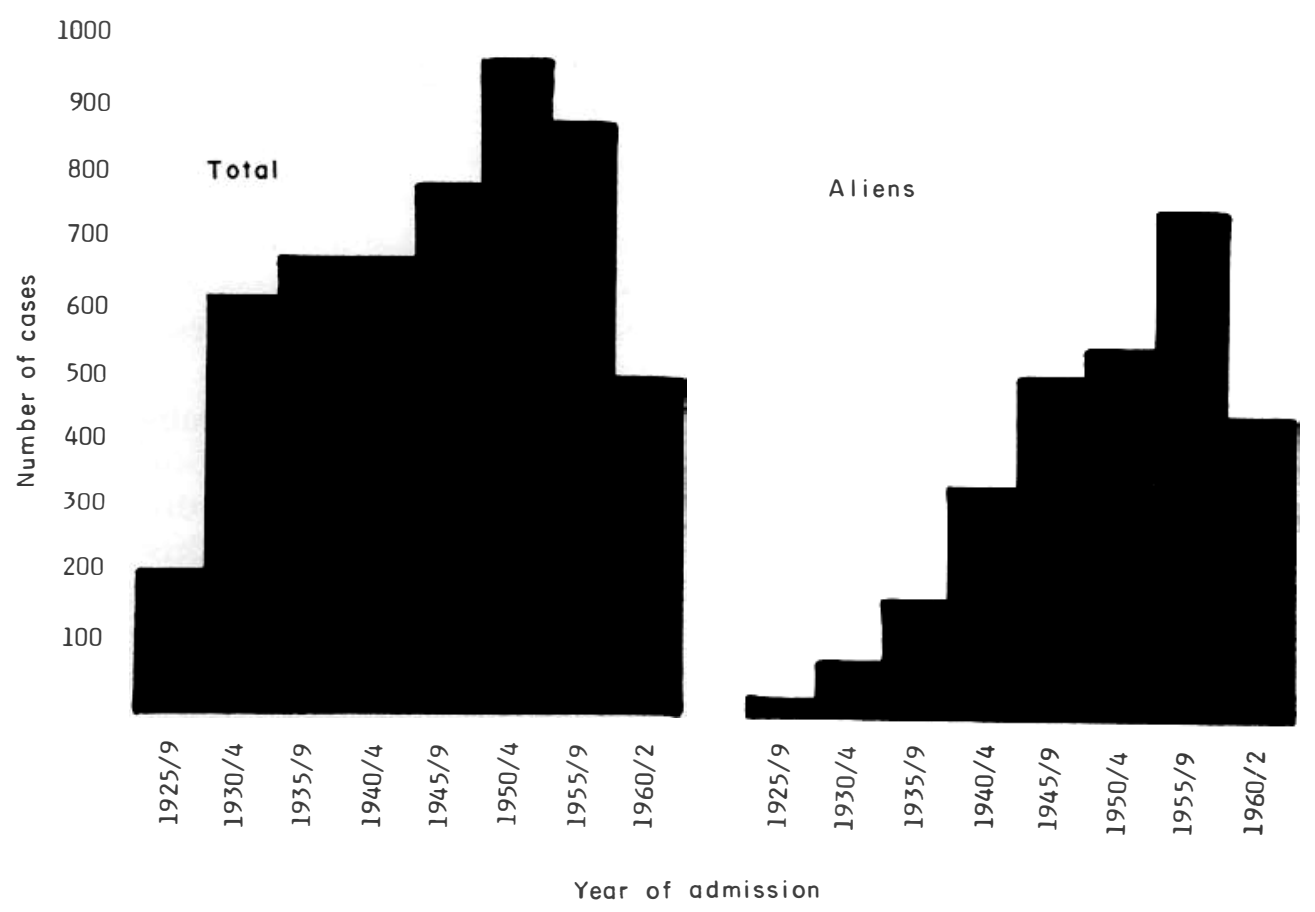

Figure 2. Comparison of total and alien cases admitted to Mtemwa and Ngomahuru Hospitals 1925-62. 
Table 1. Total alien admissions and countries of origin to Mtemwa and Ngomahuru Hospitals, $1925-62$

\begin{tabular}{lccrrrrrrr}
\hline & 1925 & 1930 & 1935 & 1940 & 1945 & 1950 & 1955 & 1960 & \\
Country & -29 & -34 & -39 & -44 & -49 & -54 & -59 & -62 & Total \\
\hline Malawi & 3 & 40 & 88 & 119 & 131 & 152 & 313 & 180 & 1,026 \\
Moçambique & - & 18 & 33 & 97 & 189 & 246 & 301 & 182 & 1,066 \\
Zambia & - & 21 & 46 & 107 & 159 & 114 & 93 & 48 & 588 \\
Miscellaneous & - & - & 3 & 3 & 19 & 37 & 36 & 16 & 114 \\
$\quad$ Total & 3 & 79 & 170 & 326 & 498 & 549 & 743 & 426 & 2,794 \\
\hline
\end{tabular}

Table 2. Geographic distribution of cases admitted to Mtemwa and Ngomahuru Hospitals $1925-62$

\begin{tabular}{lrrrrrrrrr}
\hline & 1925 & 1930 & 1935 & 1940 & 1945 & 1950 & 1955 & 1960 & \\
Province & -29 & -34 & -39 & -44 & -49 & -54 & -59 & -62 & Total \\
\hline Manicaland & 8 & 41 & 65 & 50 & 77 & 111 & 117 & 59 & 528 \\
Mashonaland N. & 3 & 26 & 119 & 107 & 86 & 208 & 189 & 126 & 864 \\
Mashonaland S. & 185 & 266 & 185 & 136 & 172 & 195 & 171 & 55 & 1,365 \\
Midlands & 2 & 71 & 89 & 130 & 161 & 153 & 100 & 78 & 784 \\
Matabeleland N. & - & 9 & 68 & 50 & 66 & 56 & 99 & 88 & 436 \\
Matabeleland S. & - & 23 & 44 & 64 & 66 & 60 & 41 & 30 & 328 \\
Victoria & 10 & 191 & 106 & 141 & 145 & 186 & 148 & 67 & 994 \\
$\quad$ Total & 208 & 627 & 676 & 678 & 773 & 969 & 865 & 503 & 5,299 \\
\hline
\end{tabular}

ages of onset and sex (Fig. 3) and types of presentation (Fig. 4). The latter is not necessarily a true picture, as many patients had probably suffered from the disease for long periods before admission and their clinical status had changed.

Numerous forms of treatment were used. Chaulmoogra oil, obtained from Hydnocarpus kurzii apparently showed encouraging results and the Forestry Department undertook experimental growth of the trees, a project which did not reach fruition.

Sulphetrone, and later dapsone, were introduced into Zimbabwe in the 1950s, and were spectacular in their success in the management of new and established cases. In the erroneous belief that these drugs would dramatically reduce the numbers of cases and that leprosy was no longer a problem, the Ministry of Health withdrew its support from Mtemwa in 1963. Many patients were discharged with no follow-up treatment. Other patients, many badly crippled and for whom no other home existed, remained at Mtemwa under the care of the Department of Social Welfare and were assisted by the Friends of Mtemwa, which later became the Rhodesia Leprosy Association.

A big step forward occurred in 1966 with the abandonment of compulsory hospitalization for all leprosy patients, and the establishment of out-patient treatment clinics. One such facility was the Tropical Diseases Unit at Harare Hospital in Salisbury, which was subsequently enlarged to accommodate 27 designated beds. Ngomahuru finally closed as a leprosy hospital in 1971, and the Leprosy Repression Act was repealed in 1974. 


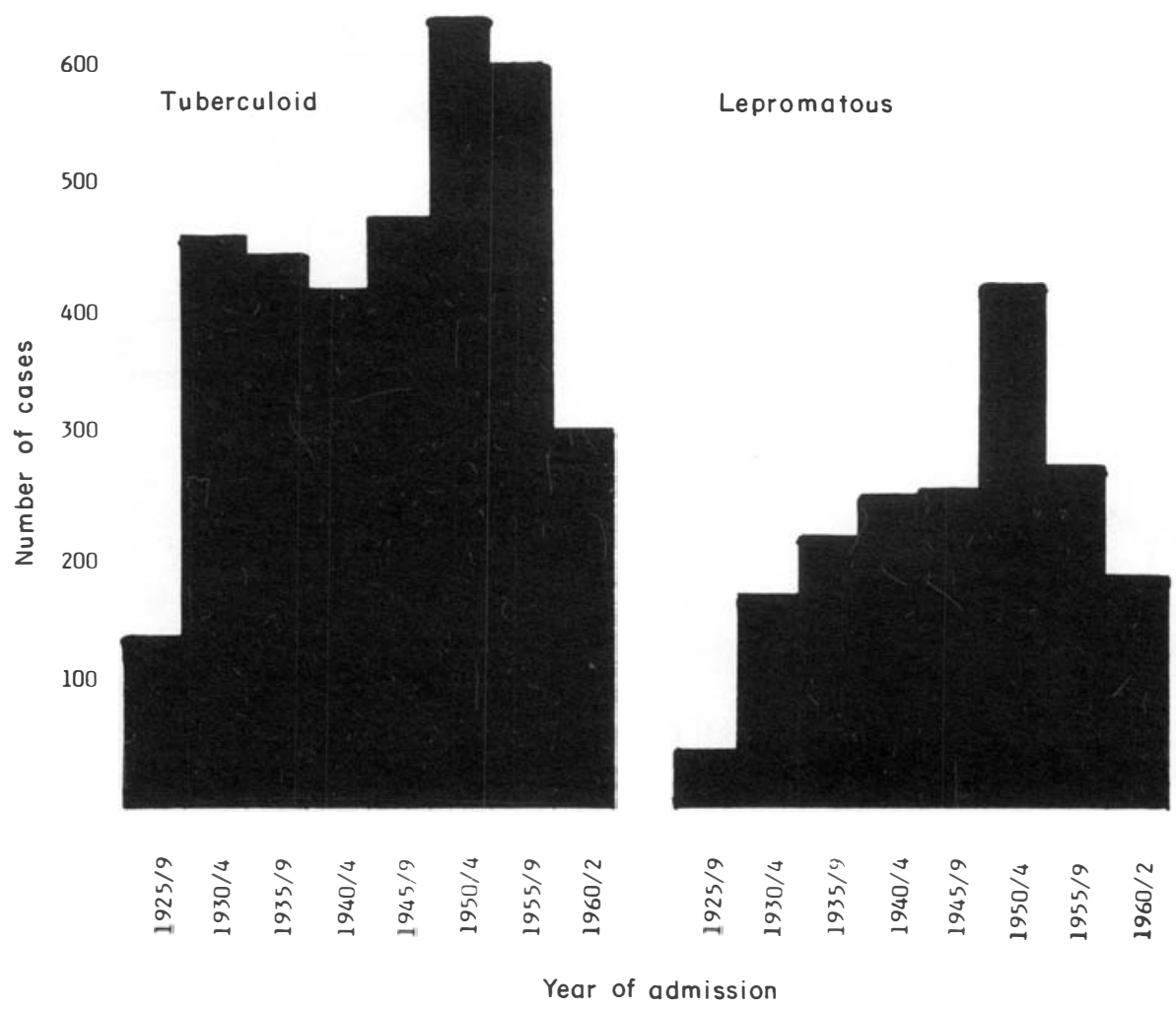

Figure 3. Type of presentation of patients admitted to Mtemwa and Ngomahuru Hospitals, $1925-62$.

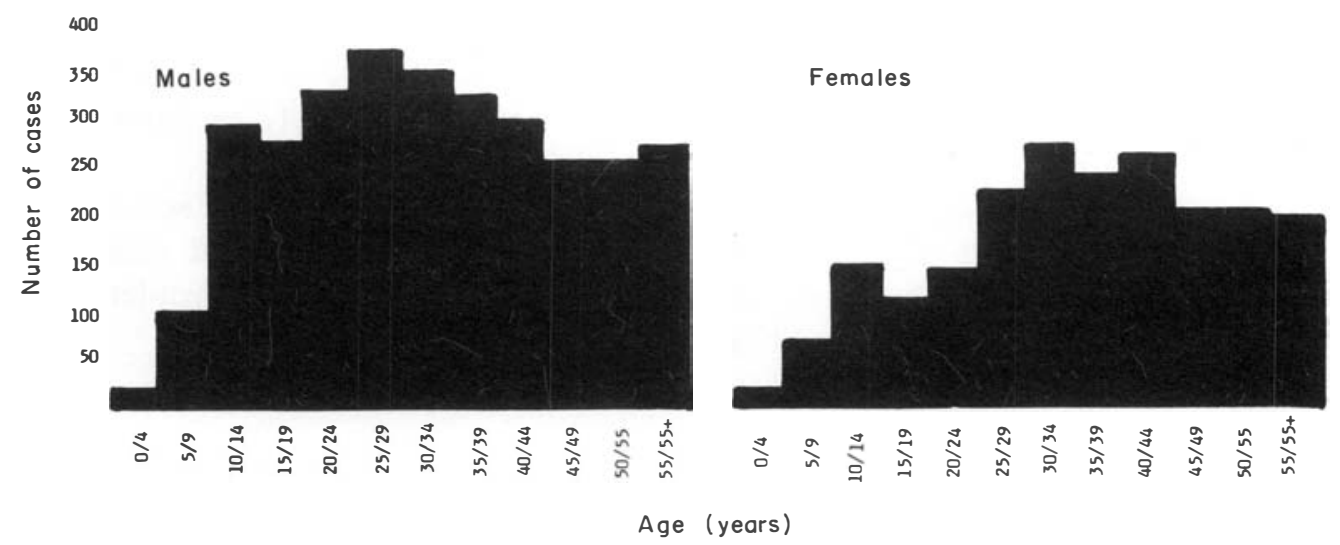

Figure 4. Sex and age of onset of symptoms of patients admitted to Mtemwa and Ngomahuru Hospitals, 1925-62. 
Table 3. New cases since 1962

\begin{tabular}{|c|c|c|c|c|c|}
\hline Year & Cases & Year & Cases & Year & Cases \\
\hline 1963 & 402 & 1969 & 228 & 1975 & 362 \\
\hline 1964 & 290 & 1970 & 411 & 1976 & 334 \\
\hline 1965 & 323 & 1971 & 467 & 1977 & 183 \\
\hline 1966 & 233 & 1972 & 547 & 1978 & 240 \\
\hline 1967 & 302 & 1973 & 445 & 1979 & 273 \\
\hline 1968 & 397 & 1974 & 455 & Total & 5,892 \\
\hline
\end{tabular}

\section{Leprosy - modern concepts}

The numbers of new cases seen since 1962 are shown in Table 3. Undoubtedly, many more cases exist but various factors, including the bush war and failure to recognize symptoms, have contributed to their omission. A review ${ }^{2}$ of 1,523 patients shows that in $31.1 \%$ the presenting prodromal symptoms were not skin lesions and that in $35.3 \%$ of those presenting with lesions diagnosis would be missed without whole-body examination. Known cases are indexed at Provincial Officer of Health level and regular leprosy review clinics are held in the more remote areas.

Now that the disease is more easily managed, and without the insidious methods of control previously used, many new cases come forward for treatment - often encouraged by family and friends. This trend must be actively pursued in view of the social and geographic upheaval experienced by the population during the war. Unnatural overcrowding in refugee camps and protected villages (established to denude large areas of the country of people who would otherwise feed and shelter guerrilla combatants) could lead to an upsurge in cases in future years.

With much of the overseas aid given since independence being used to redevelop rural areas, the Ministry of Health is training large numbers of community health workers who will play a vital role in early recognition of leprosy and channel patients towards treatment.

Leprosy has a wide geographic variation in Zimbabwe, and some areas produce considerably more patients than others. It is hoped that epidemiological studies currently being undertaken will elucidate this problem and provide a basis for future control measures.

\section{References}

1 Fraser Ross W. The effects of war on Rhodesian health services. C Afr J Med 1979; 25: $266-8$.

2 Ellis BPB, Thomas JEP. First lesion sites in leprosy. C Afr J Med 1976; 22: 96-7.

3 Leprosy Repression Act Statute Law of Southern Rhodesia, rev. edn, 1939: III; ch. 142. 